\title{
Cash Flow Risk Management Pratices dan Sustainable Financial Performance Pada Industri Perbankan Di Indonesia
}

\author{
Sparta $^{1}$ \\ ${ }^{1}$ Indonesia Banking School \\ e-mail : ${ }^{1}$ sparta@ibs.ac.id

\begin{tabular}{ccc}
\hline Diterima & Direvisi & Disetujui \\
$31-01-2022$ & $17-02-2022$ & $23-02-2022$ \\
\hline
\end{tabular}

\begin{abstract}
Abstrak - Penelitian ini bertujuan untuk melihat sejauh mana praktik manajemen risiko pada perusahaan khususnya perbankan berpengaruh terhadap keberlangsungan kinerja keuangan perbankan konvensional di Bursa Efek Indonesia. Sampel penelitian adalah industri perbankan di pasar modal BEI selama periode 2017 sampai 2019. Dari 41 bank yang go public, 38 bank konvensional digunakan sebagai sampel penelitian. Variabel dependen yang digunakan adalah Sustainable growth rate sebagai proksi kinerja pembiayaan berkelanjutan. Variabel independen yang digunakan adalah arus kas operasi terhadap total kewajiban sebagai proksi praktik manajemen risiko dalam arus kas operasi, arus kas investasi terhadap total kewajiban, arus kas pembiayaan ke total kewajiban dan arus kas operasi ke ekuitas pemegang saham. Hasil penelitian menunjukkan bahwa praktik manajemen risiko pada arus kas keuangan terhadap total kewajiban, praktik manajemen risiko dalam investasi arus kas terhadap total kewajiban, praktik manajemen risiko pada arus kas operasi terhadap total ekuitas pemegang saham berdampak pada keberlanjutan kinerja keuangan perbankan. Hasil tersebut berimplikasi pada manajemen perbankan terutama dalam hal memprediksi keberlanjutan kinerja keuangan perbankan.
\end{abstract}

Kata Kunci : sustainable financing performance, cash flow risk management pratices

Abstract - This study aims to see the extent to which risk management practices in companies, especially banking, influence the sustainability of conventional banking financial performance on the Indonesia Stock Exchange. The research sample is the banking industry on the IDX capital market during the period 2017 to 2019. Of the 41 banks that went public, 38 conventional banks were used as research samples. The dependent variable used is the Sustainable growth rate as a proxy for sustainable financing performance The independent variables used are Cash flow operating to total liability as a proxy for risk management practice in cash flow operating, cash flow investing to total liability, cash flow financing to total liability and cash flow operating to shareholder equity. The results show that risk management practices in cash flow finance to total libility, risk management practices in cash flow investing to total liability, risk management practices in cash flow operating to total share holder equity have an impact on the sustainability of banking financial performance. These results have implications for banking management, especially in terms of predicting the sustainability of banking financial performance.

Key Words: sustainable financing performance, cash flow risk management pratices 


\section{PENDAHULUAN}

Penelitian berfokus bagaimana dampak praktek Risk Management Cash Flows terhadap Suitainable Finance Performance. Keberlanjutan kinerja keuangan telah menjadi fokus sebagian negara di dunia. Hal ini mengingat banyak perusahaan yang bisa jatuh tiba-tiba dalam waktu semalam karena masalah praktek manjemen risiko arus kas. Kas merupakan darah perusahaan yang perlu dijaga keseimbangannya. Penelitian ini sangat menarik dilakukan karena banyaknya masalah kerberlanjutan kinerja keuangan menjadi masalah sangat penting dalam going concern perusahaan. Perusahan yang diteliti dalam penelitian ini adalah industri perbankan yang go public di BEI.

Pengelolaan arus kas sangat penting bagi perusahaan. Sebelum era SAK tahun 1994, jenis laporan keuangan yang wajib dilaporkan adalah laporan posisi keuangan (neraca), laba rugi dan laporan perubahan modal (atau laporan perubahan laba ditahan) serta catatan atas laporan keuangan. Namun sejak tahun 1994 jenis laporan keuangan ditambah satu lagi yaitu dengan mewajiban bagi perusahaanperusahaan untuk menyajikan laporan keuangan arus kas.

Pentingnya pengelolaan arus kas dimata investor pasar modal ditandai dengan peranan informasi arus kas operasi dalam pengambilan keputusan investor pasar modal untuk membeli atau menjual saham yang mereka pegang atau saham yang akan dibeli. Dengan demikian dalam penelitian ini mencoba untuk melihat sejauh mana praktek manjemen risiko dalam perusahan khususnya perbankan dalam mempengaruhi keberlanjutan kinerja keuangan perbankan. Untuk itu peneliti tertarik untuk meneliti bagaimana praktek manajemen risiko arus kas dan keberlanjutan kinerja keuangan perusahaan khususnya industri perbankan di Indonesia.

Tingkat pertumbuhan akuntansi berkelanjutan digunakan oleh manajer keuangan dan bankir untuk menentukan kemungkinan kebutuhan pembiayaan dan peluang investasi bagi perusahaan (Burger dan Hamman, 1990), SGR arus kas (CFSGR), yang didefinisikan sebagai tingkat di mana perusahaan dapat tumbuh dengan tetap mempertahankan saldo kas target di neraca. Hubungan antara akuntansi SGR dan CFSGR kemudian diselidiki. Hasil penelitiannya menemukan bahwa walaupun akuntansi SGR tidak dipengaruhi oleh komponen non tunai dari modal kerja, atau oleh perubahan dalam komponen modal kerja non tunai, namun CFSGR terpengaruh oleh variabel tersebut. Kedua tingkat tersebut dipengaruhi oleh profitabilitas perusahaan. SGR akuntansi dipengaruhi oleh pertumbuhan penjualan, sedangkan CFSGR tidak. Para penulis tidak berpendapat bahwa CFSGR harus menggantikan SGR akuntansi, tetapi demi kepentingan terbaik, selayaknya perusahaan memperhatikan CFSGR dan implikasinya terhadap pertumbuhan dan posisi kas perusahaan.

Wadesango N, Tinarwo N, Sitcha L, and Machingambi S, (2019), melakukan penelitian pada Usaha Kecil dan Menengah di Zimbabwe. Hasil bahwa sebagian besar praktik pengelolaan kas yang dilakukan oleh UKM secara signifikan berpengaruh terhadap profitabilitas dan Sustanable Growth Rate Perusahaan tersebut. Hasil penelitian juga mengungkapkan bahwa sebagian besar UKM enggan menerapkan praktik cash management secara efektif, sehingga mereka gagal.

Penelitian ini merupakan replikasi dari penelitian Wickamasinghe dan Gunwardane (2017). Ia meneliti praktek risk management arus kas dan dampaknya terhadap Sustainable Financial Performance atau disingkat dengan SFP selama kurun waktu tahun 2016 . Perbedaan penelitian ini dengan penelitian Wickamasinghe dan Gunwardane (2017) adalah pertama periode penelitian selama tiga tahun terakhir yaitu tahun 2017, 2018 dan 2019. Kedua adalah perusahaan yang diteliti berbeda, pada penelitian ini diteliti untuk industri perbankan sedangkan penelitian Wickamasinghe dan Gunwardane (2017) adalah industry non bank dan ketiga adalah pada penelitian ini menggunakan variabel kontrol Size sedangkan penelitian Wickamasinghe dan Gunwardane (2017) tidak menggunakan variable kontrol Size.

Dari uraian latar belakang di atas, maka dapat disusun rumusan masalah penelitian sebagai berikut: 1). Bagaimana dampak praktek manajemen risiko dalam arus kas operasi terhadap sustainable financial performance perbankan? 2), Bagaimana dampak praktek manajemen risiko dalam arus kas investasi terhadap sustainable financial performance perbankan? 3). Bagaimana dampak praktek manajemen risiko dalam arus kas pembiayaan terhadap sustainable financial performance perbankan? 4). Bagaimana dampak praktek manajemen risiko dalam arus kas operasi ke pemegang saham terhadap sustainable financial performance perbankan?

Penelitian ini hanya meneliti perbankan konvensional go publik di BEI saja dengan tahun penelitian 2017 sampai dengan 2019. 
Tujuan penelitian ini adalah untuk 1. Untuk mengetahui dampak praktek manajemen risiko dalam arus kas operasi terhadap sustainable financial performance perbankan, 2. Untuk mengetahui dampak praktek manajemen risiko dalam arus kas investasi terhadap sustainable financial performance perbankan. 3. Untuk mengetahui dampak praktek manajemen risiko dalam arus kas pembiayaan terhadap sustainable financial performance perbankan. 4. Untuk mengetahui dampak praktek manajemen risiko dalam arus kas operasi ke pemegang saham terhadap sustainable financial performance perbankan

Hasil ini sangat berguna untuk melihat praktik manajemen risiko arus kas yang sangat bermanfaat dalam mitigasi risiko manajemen arus kas dan dampaknya terhadap keberlanjutan kinerja keuangan perusahaan khususnya perbankan. Hasil analisis penelitian nantinya akan berguna bagi lembaga otoritas dan organisasi lainnya untuk meningkatkan praktik pengelolaan risiko arus kas dan kebijakan untuk meningkatkan praktik manajemen risiko arus kas. Hasil penelitian ini dapat digunakan sebagai referensi untuk pengetahuan yang ada terkait dengan praktik pengeloaan risiko arus kas.

\section{REVIU LITERATUR DAN HIPOTESIS Stakeholders Theory}

Stakeholders theory atau teori pemangku kepentingan adalah teori manajemen organisasi dan etika bisnis yang membahas moral dan nilai-nilai dalam mengelola organisasi (Wickamasinghe dan Gunwardane, 2017). Freeman (1984) mengungkapkan suatu organisasi telah efektif mengelola hubungan antar pemangku kepentingan perusahaan sehingga perusahaan tersebut dapat bertahan hidup lebih lama dan memiliki kinerja yang lebih baik. Laplume et al. (2008) menyatakan bahwa dalam teori pemangku kepentingan, perusahaan memiliki tanggung jawab kepada pemangku kepentingan dengan potensi dampak sosial yang positif ataupun negatif pada masyarakat lingkungannya. Dengan demikian, seorang manajer perusahan harus terus menerus memperhatikan kepentingan dari setiap stakeholder agar kelangsungan usaha tetap terjamin. Untuk itu, agar pemangku terjaga kepentingannya, maka manejer harus mengoperasikan perusahaan dengan menciptakan laba yang maksimal tanpa merusak kepentingan sosial dan lingkungan sehingga semua stakeholder bisa sejahtera.

\section{Agency Theory}

Teori keagenan menjelaskan hubungan antara agen dan prinsipal atau pemegang saham. Kedua pihak memiliki beda kepetingan. Pihak agen memiliki kepentingan untuk mendapatkan laba sebesarbesarnya agar memperoleh bonus sedangkan pihak prinsipal memiliki kepentingan untuk mendapat dividen yang tinggi sehingga laba tunai sangat diperlukan dibandngan dengan akrual. Bonus dihitung dari laba akrual sedangkan dividen dibagikan dengan pertimbangan laba tunai atau arus operasi yang tinggi. Dengan kebijakan deskresi akrual, laba akrual jauh lebih tinggi dibandingkan degan laba tunai sehingga kemampuan perusahan untuk membayar dividen menjadi rendah. Disini timbul konflik kepentingan. Untuk menekan konflik kepentingan ini maka perusahan harus mengeluarkan biaya monitoring. Agen bertanggung jawab meminimalkan risiko dan menghasilkan laba tunai bagi pemegang saham (Jensen,1986); Disamping hal tersebut, Agen bertanggung jawab untuk memahami risiko arus kas dan menerapkan praktik terbaik untuk memitigasi risiko di sana dengan menghasilkan laba dan kembali ke pemegang saham utama.

Usaha manajemen risiko telah menjadi trend saat ini dan telah menjadi tanggungjawab manajemen untuk melakukan sutainable pertumbuhan dan tentu saja harus juga berfokus pada sustainable financial peformance. Manajemen risiko yang baik akan meningkatkan dan mengimprovement sustainable financial performance

\section{Value at Risk (VAR)}

Value at risk digunakan sebagai alat manajemen risiko dan metode informasi tentang risiko perusahaan (Sounders and Cornett, 2018). Pengukuran risiko penting bagi stockholders untuk memahami corporate suistainable (Demireli, E.,\& Ozt Urk, B.,2009). Dengan adanya ukuran risiko perusahaan maka stocholders bisa memprediksi tingkat keberlanjutan operasional perusahaan. VAR memerlukan informasi tingkat inflasi, suku bunga, nilai tukar, risiko pasar dan harga saham untuk periode tertentu untuk memperkirakan tingkat rsiko keberlanjutan perusahan dimasa datang (Sounders and Cornett, 2018). Kesulitan adanya ketidakpastian terkait dengan faktor-faktor tersebut juga dipengaruhi atau dapat berubah-ubah sewaktu-waktu sesuai dengan kondisi pasar. Hasil VAR dapat 
digunakan sebagai dasar keputusan investasi terkait dengan asset dan kewajiban dalam rangka pembentukan portfolio investasi (Cronje, Atahau and Sparta, 2017).

\section{Cash Flow at Risk (CF at R)}

Cash flow at risk adalah adalah sebagai alat pengukuran risiko. CFR mengukur tingkat probabilitas yang tinggi dari peristiwa dan transaksi yang menimbulkan dampak kerugian dari nilai arus kas yang akan terjadi dimasa datang. Model CFR sebagai bentuk VAR untuk menemukan risiko keseluruhan terhadap arus kas organisasi Vural, O. (2004).

Tingkat kas suatu perusahaan sangat tergantung pada siklus kas masuk dan kas keluar. Pada tingkat level tertentu manajer harus bisa memperhitungkan suatu kas operasi tersebut akan mismatch sehingga terjadi defisit risiko kas operasi. Kas operasi yang defisit akan menurunkan tingkat kepercayaan investor terhadap perusahaan dan juga kepada manejernya. Tingkat cash flow perusahaan akan memengaruhi strategi pengembangan dan investasi perusahaan dimasa datang. Pada saat kondisi mengarah kepada kemungkinan kerugian maka mananajemen keuangan harus memperhitungkan langkah-langkah sehingga risko arus kas dapat dikurangi.

\section{Cash Flow Modeling}

Cash Flow modeling adalah permodelan dari arus kas agar perusahan dapat melakukan pengelolaan solvabilitasnya secara proaktif (Brigham and Houston, 2020). Pengelolaan ini dilakukan dengan target-target sumber arus kas dengan pengeluaran sehingga solvabilitas perusahaan dapat terjaga. Permodelan ini dapat memberikan pengetahuan bagi manajemen atas pencapaian target arus kas yang telah ditentukan sehingga dampak arus kas kepada permodalan perusahaan dapat dipahami oleh manajemen. Hal ini dapat meminialkan risiko terkait dengan keberlanjutan usaha dan tujuan perusahan (Brigham and Houston, 2020).

\section{1) Financial Hedging}

Financial hedging atau lindung nilai finansial merupakan instrumen keuangan yang digunakan untuk lindung nilai aset dengan tujuannya adalah untuk mestabilkan nilai dalam jangka panjang, sehingga membantu mempertahankan arus kas operasi dimasa datang. Alat lindung nilai dan pendekatan manajemen praktis untuk mendefinisikan risiko dan menstabilkan kemampuan solvabiitas jangka panjang secara kuantitatif dan akan membantu mempertahankan arus kas operasi yang kuat (Hiller et al, 2012). Semua alat Hedging digunakan untuk memantau dan mengukur serta mengendalikan risiko arus kas (Hull, 2018).

\section{2) Liquidity Risk Management Practices}

Pengelolaan risiko likuiditas yang baik dapat dilakukan dengan penguasaan uang tunai untuk pemenuhan kewajiban keuangan perusahaan. Pengelolaan likuiditas sangat penting untuk memonitor kewajiban operasi, investasi, dan kewajiban keuangan bisnis lainnya (Sounders and Cornett, 2018).. Banyak perusahaan mengalami kebankrutan yang diawali dari kesulitan likuiditas, rendahnya aset lancar yang dimiliki sehingga terakumulasi kesulitan dalam pemenuhan kewajibannya. Ada hubungan negatif antar kemampuan perusahaan dalam menghasilkan uang, pengelolaan likuiditas dan kinerja keuangan. Semakin rendah kemampuan perusahaan dalam menghasilkan uang maka semakin rendah kemampuannya dalam mengelola likuiditas sehingga berdampak kepada rendahnya kinerja keuangan perusahaan. Dalam jangka panjang hal ini akan mengganggu sustainable financial performance perusahaan.

\section{3) Meninjau dan Memantau Sistem Manajemen Kas Secara Teratur.}

Manajemen harus melakukan review terhadap CFO untuk memastikan apakah varians kas yang ada masih dalam tahap yang aman untuk menimalkan risiko arus kas. Dengan demikian perusahan harus memiliki data keuangan yang andal. Perlu manajemen kas yang baik dan teratur agar kemampuan likuiditas peusahaan terjaga dan memastikan tidak ada kebutuhan kas yang tidak terpenuhi.(Brigham and Houston, 2020)

\section{4) Mengembangkan Model Proyeksi Kas yang Akurat.}

Model proyeksi kas sangat penting dilakukan oleh perusahaan dalam meyakinkan apakah untuk periode jangka pendek perusahaan masih dalam kondisi likuid atau tidak likuid. Sehinga perlu diproyeksi sumber-sumber dana kas dan pengeluaran kas perusahaan. Proyeksi arus kas terkait dengan musim harus dirancang sedemikian rupa sehingga bentuk trend musiman mingguan, bulanan, kuartalan dan semesteran menunjukkan kondisi riil yang akan dihadapi oleh perusahaan. Jadi data-data keuangan harus akurat. Data akurat bila periodenya semakin pendek, misalnya dalam periode musiman, bulanan, 
harian, pola dan tren siklus dan dapat jangka panjang, menengah dan pendek. Modul proyeksi kas sangat membantu dalam mitigasi risiko arus kas atau risiko likuiditas.

Hal lain yang perlu dipertimbangkan dalam membuat model proyeksi kas adalah pertama perusahaan harus memiliki database pelanggan yang tepat, persyaratan \& ketentuan serta pelunasan yang cepat dari pelanggan sangat penting. Kedua adalah adanya perlakuan yang adil kepada vendor atau pemasok. Jika pembayaran tidak diselesaikan dengan cepat dan tepat waktu akan berdampak pada gangguan suply bahan baku ataupun keperluan operasi perusahaan. Hal ini akan berdampak lanjutan, dimana perusahaan juga tidak mampu menyediakan barang dan jasa kepada pelanggannya sehingga tingkat perusahan untuk mendapatkan kas terganggu. Banyak perusahaan mengeluhkan kurang pelanggan karena mereka tidak mampu melayani tepat waktu kepada pelanggannya sehingga pelanggan lari ke perusahaan lainnya.

Cara lain yang ketiga adalah perlunya kontrol atas hasil investasi perusahaan. Kontrol atas hasil investasi perusahaan dengan memiliki kebijakan investasi tertulis yang jelas dan terkini akan menjadi pedoman bagi manager keuangan dan manajer lain untuk mengambil keputusan cepat ketika ada peluang. Menurut (Brigham and Houston, 2020) kurangnya praktik manajemen arus kas dan pengetahuan bisnis yang buruk sebagai alasan utama runtuhnya bisnis. Lebih lanjut tindakan menahan uang tunai, pemberian kredit yang tidak tepat dan tidak terkontrol, catatan bisnis serta manajemen inventaris yang buruk dan lainnya adalah kurangnya pengalaman manajemen merupakan salah satu penyebab utama terjadinya risiko.

Langkah keempat yang harus diakukan oleh seorang Chief Financial Officer (CFO) adalah dengan menyusun emergency backup plan. Rencana ini disusun untuk menghadapi risiko terburuk yang akan terjadi terkait dengan risiko, sehingga perusahaan mempunyai backup dana untuk recovery bila kondisi terburuk betul-betul terjadi dikemudian hari. Dengan demikian, CFO harus mempunyai jaringan dengan lembaga keuangan perbankan untuk bisa dipercaya daam rangka mendapat dana untuk mengatasi risiko terburuk yang akan terjadi dikemudian hari tersebut. CFO harus memiliki ases yang lebih fleksibel ke lembaga keuangan dan mitra sesama perbankan.

Langkah ke lima adalah melakukan otomatisasi proses manajemen kas. Dengan otomisasi ini memudahkan CFO dalam mengelola kas sehingga lebih produktif dalam bentuk peningkatan arus kas. Beberapa alat dan perangkat lunak control atas arus kas banyak tersedia di pasar untuk menstabilkan praktik arus kas dan mengurangi risiko. Sebagian besar perusahaan yang terdaftar kebanyakan menggunakan sistem ERP dan menerapkan alat mitigasi risiko arus kas.

Langkah keenam adalah menjaga pertumbuhan secara prudential. Pertumbuhan perusahaan sangat cepat akan membawa risiko yang tinggi. Misalnya pertumbuhan kredit yang sangat tinggi juga membawa kepada risiko kredit yang sangat tinggi juga. Secara total, pertumbuhan asset bank yang sangat tinggi dalam periode tertentu juga akan berdampak pada risiko yang tinggi. Sehingga hal ini perlu dijaga pertumbuhan dengan cukup hati-hati. Pertumbuhan bisnis dengan waktu singkat akan berisiko tinggi.

Langkah terakhir adalah CFO harus mempunyai kemampuan dalam mengidentifikasikan masalah lebih awal sehingga kejadian terburuk dapat dideteksi lebih awal. Kejadian baru yang dapat terdeteksi lebih awal akan memudahkan perusahaan dalam mebuat dan menyiapkan langkah-langkah pencegahan. Sehingga hal ini dapat meningkatkan arus kas lebih baik.

\section{Sustainabilty}

Sutainability atau keberlanjutan adalah bagaimana caranya untuk mencari peningkatan sumbersumber pendapatan baru, dengan demikian mengurangi pengeluaran dan meningkatkan efisiensi untuk menciptakan nilai pemangku kepentingan jangka panjang (Wickamasinghe dan Gunwardane, 2017). Dalam kondisi dunia bisnis saat ini, strategi untuk mendapatkan keuntungan dari pengambilan keputusan berkelanjutan dalam menghasilkan pendapatan, mengendalikan biaya, membangun kepercayaan pada nilai pemangku kepentingan dan manajemen risiko, telah menjadi fitur yang lebih penting daripada hanya mendapatkan laba akuntansi tradisional.

\section{1) Sustainable financial Performance}

Hubungan antara keberlanjutan dan kinerja keuangan dianggap sebagai skenario yang lebih kompleks. Hal ini karena ketidaktersediaan metode standar untuk mengukur keberlanjutan. Namun demikian area keberlanjutan tersebut mencakup sejumlah besar kepedulian terhadap sosial, ekonomi dan lingkungan. Kinerja keuangan lebih sempit dalam ruang lingkup dan pengukuran.

\section{2) Sustainable Growth Rate (SGR)}


Tingkat pertumbuhan berkelanjutan (SGR) didefinisikan sebagai tingkat pertumbuhan maksimum yang mampu dimiliki bisnis tanpa mendapatkan sumber dana dari pihak luar. Lebih jauh Subbareddy dan Reddy (2017) menyatakan bahwa SGR didefinisikan sebagai pertumbuhan yang mampu dilakukan perusahaan, tidak mengubah struktur modalnya. Struktur modal perusahaan adalah campuran hutang dan ekuitas yang digunakan untuk membiayai perusahaan dalam jangka panjang. SGR adalah suatu cara untuk mengindikasikan seberapa jauh dan seberapa cepat suatu bisnis dapat berkembang tanpa meminjam atau dari dana internal. Setelah perusahaan memutuskan tingkat SGR ini, maka perusahaan tersebut harus menggunakan dana internal untuk memfasilitasi pertumbuhan tambahan. SGR perusahaan adalah laba terhadap ekuitas (Return on equity atau disingkat ROE) dan persentase dividen terhadap saldo laba perusahaan (Divident payout ratio). semakin rendah DPR nya maka semakin tinggi SGR nya. Hal ini karena dana internal banyak yang dinvestasikan kembali sehingga akan menaikkan SGR. Formulasi SGR dihitung sebagai berikut (Wickramasinghe dan Gunawardane, 2017):

\section{SGR = ROE x (1 - Dividend-Pay-Out Rate).}

Dalam penelitian ini ukuran sustainable financial performance menggunakan SGR dengan formulasi seperti di atas.

\section{Variabel Control Size Perbankan}

Ukuran perusahaan menggambarkan total aset perusahaan. Perusahaan besar dan perusahaan kecil memengaruhi sustainable financial performance. Dalam kaitannya dengan perbankan besar dan kecil juga diperkirakan ikut memengaruhi sustainable financial performance. Dalam penelitian ini digunakan variabel kontrolnya yaitu ukuran bank (SIZE).

\section{Penelitian Sebelumnya yang Relevan}

Wickramasinghe dan Gunawardane (2017), meneliti dampak cash flow management practice terhadap sustainable financial performance di Sri Lanka. Tujuan penelitiannya adalah untuk mengeksplorasi dampak dari praktik manajemen risiko dan bagaimana mereka menerapkannya untuk mencapai kinerja keuangan berkelanjutan di Sri Lanka dan menawarkan panduan kepada semua bisnis tentang bagaimana mereka dapat memitigasi risiko yang mereka hadapi. Sektor usaha yang diteliti adalah semua sektor yang diwakili sebanyak 65 emiten dari 295 perusahaan yang listing dari tahun 2011 sampai 2015 di Sri Lanka. Analisis statistik dari teknik regresi berganda dilakukan untuk menghitung hasil dengan menggunakan software e view-9. Praktik manajemen risiko dalam arus kas operasi dan financing memiliki korelasi negatif dengan kinerja keuangan berkelanjutan. Hasil penelitian menunjukkan bahwa praktik manajemen risiko arus kas investasi tidak memiliki korelasi dengan kinerja keuangan berkelanjutan. Ini akan memberikan gambaran rinci tentang keterlibatan praktik manajemen risiko arus kas dan pentingnya hasil ini bagi perusahaan-perusahaan yang terdaftar di Sri Lanka dalam memprediksi SGR nya dari sisi manajemen risiko dalam arus kas operasi, financing dan investasi..

Shao, Zhengyan (2018), melakukan studi di China pada 46 perusahan didalam industri tekstil dan garment yang terdaftar di Shanghai and Shenzhen Stock Market, dengan data 2008-2011, dengan menguji apakah input moneter dan debt ratio berpengaruh terhadap SGR . Alat uji nya menggunakan Wilcoxon Signed-Rank Test. Hasil penelitian menunjukkan bahwa pada era paska krisis, input moneter yang besar, rasio hutang yang tinggi dan dominasi tekstil dengan nilai tambah rendah dalam struktur pendapatan menjadi penyebab utama kegagalan emiten dalam mencapai sustainable growth of sales revenue.

Manaf, Normaisarah, Saad, Azhar dan Norfhadzilahwati (2018), melakukan studi untuk melihat faktor-faktor penentu SGR dengan menggunakan variabel; independen ukuran perusahan, rasio lancar, deviden per share, dan net profit margin. Sampel penelitian sebanyak 450 perusahan shariah yang listing di Bursa Saham Malaysia, periode penelitiannya adalah 10 tahun dari tahun 2004 sampai dengan 2014. Hasilnya menujukan bahwa ukuran perusahaan, dan net profit margin signifikan positif mempengaruh SGR, dan rasio deviden per share mempengaruhi negatif signifikan terhadap SGR. Rasio lancar tidak mempengaruhi SGR perusahan syariah di Malaysia.

Priyanto, Aldi dan Robiyanto (2020), melakukan studi yang bertujuan memberikan bukti empiris berpengaruh atau tidaknya, likuiditas, leverage, dan efisiensi terhadap SGR. Populasi penelitiannya adalah perusahan manufaktur yang terdafftar di Bursa Efek Indonesia. Jumlah sampel 50 perusahaan dengan periode penelitian 2015-2018. Data dianalisis dengan teknik regresi data panel. Hasilnya 
penelitiannya menunjukkan bahwa likuiditas dan turnover aset tidak berpengaruh signifikan terhadap SGR sedangkan leverage berpengaruh positif terhadap SGR. Penelitian ini menjelaskan bahwa SGR sangat penting karena berkaitan dengan strategi yang digunakan perusahaan agar dapat mengalami pertumbuhan berkelanjutan.

Wadesango N, Tinarwo N, Sitcha L, and Machingambi S, (2019), melakukan penelitian pada Usaha Kecil dan Menengah di Zimbabwe. Tujuan penelitiannya adalah untuk mengklasifikasikan praktik manajemen arus kas yang saat ini dilakukan oleh UKM Zimbabwe dan mencoba untuk mengetahui efek dari praktik tersebut terhadap profitabilitas dan keberlanjutan UKM. Dalam penelitian ini ia menggunakan pendekatan penelitian kualitatif dan kuantitatif. Target populasi penelitannya adalah 14 usaha kecil di Harare dan Gweru dengan total 55 peserta yang ditargetkan. Sampel dihitung menggunakan rumus Yamane yang menghasilkan 50 responden. Metode pengumpulan data yang digunakan meliputi kuesioner dan wawancara serta hasil dari metode pengumpulan data disajikan dalam bentuk tabel, grafik dan diagram lingkaran. Hasil ini dianalisis dan diuji dengan menggunakan metode uji chi square yang mengungkapkan bahwa sebagian besar praktik pengelolaan kas yang dilakukan oleh UKM secara signifikan berpengaruh terhadap profitabilitas dan Sustanable Growth Rate Perusahaan tersebut. Hasil penelitian juga mengungkapkan bahwa sebagian besar UKM enggan menerapkan praktik cash management secara efektif, sehingga mereka gagal.

\section{Kerangka Pemikiran}

Variabel penelitian terdiri dari variabel dependen sustainable financial performance (SGR), sedangkan variable dependennya adalah Risk management practices in Operating Cash Flow (RMPCFO), Risk management practices in Investing cash flow (RMPCFI), Risk management practices in Financing cash flow (RMPCFF) dan Risk Management Practice in Opertaing Cash Flow to Stockholder Equity (RMPCFOE) dengan variabel kontrol untuk mengontrol dampak ukuran bank terhadap sustainable growth rate perbankan yaitu Ukuran bank (SIZE)..

\section{Pengembangan Hipothesis}

Cash flow operating cenderung meminimalkan risiko praktek manajemen risiko dan meningkakan sutainable financial performance, semangkin tinggi CFO maka semakin rendah risk management practice dan semakin meningkatkan sustainable financial performance. Dengan demikian terjadi hubungan negatif dalam praktek risk management pada cash flow operating. Semakin tinggi angka variabel cash flow operating to total liability maka semakin rendah risk management practicenya dan semakin tinggi sustainable financial perfomance nya. Sehingga hipotesis Ha1: Risk management practices in Opearting cash flow to Total Liability berpengaruh negatif terhadap SGR

Logika theory yang sama juga berlaku untuk risk management practice dalam cash flow invetasi dan cash flow financing. Hubungan cash flow operating dengan cash flow investing dan financing adalah berhubungan negatif, semakin tinggi cash flow operating, cenderung cash flow investing dan cash flow financing turun karena dana operasi digunakan untuk expansi dan pembayaran kewajiban dan dividen. Hal ini tidak selalu demkian, terkadang cash flow operating naik belum tentu menurunkan cash flow investing dan cash flow financing. Sehingga hubungan praktik manajemen risiko pada cash flow investing dan financing bisa positif maupun negatif. Sehingga, untuk hipotesis Ha2, Ha3, Ha4 adalah dampak risk management practice dalam cash flow investing, cash flow financing, dan cash flow operasi kepada pemegang saham adalah bisa berhubungan positif dan negatif terhadap sustainable financial performance. Dengan demikian Ha2: Risk management practices in Investing cash flow to Total Liability berpengaruh terhadap SGR, Ha3: Risk management practices in Financing cash flow to Total Liability berpengaruh terhadap SGR, dan Ha4: Risk management practices in Financing cash flow to Equity berpengaruh terhadap SGR.

\section{METODE PENELITIAN Populasi dan Sampel}

Populasi penelitian ini adalah Industri Perbankan dnegan sampel perbankan yang terdaftar di BEI tiga tahun terakhir yaitu sejak tahun 2017 sampai dengan 2019. Data yang dikumpulkan adalah terkait dengan data kinerja keuangan yang berkelanjutan untuk perbankan yang terdaftar. Data laporan tahunan yang digunakan dalam penelitian ini diperoleh dari situs www.jsx.go.id.

\section{Definisi dan Pengukuran Variabel}

Data sekunder dari laporan keuangan yang di dapat disitus BEI http://www.jsx.go.id 
Definsi variabel dapat dlihat dalam tabel 1 di bawah berikut:

Tabel 1 Definisi Variabel.

\begin{tabular}{|c|c|c|c|}
\hline Variabel & definisi & formulasi & $\begin{array}{c}\text { Skala } \\
\text { pengukuran }\end{array}$ \\
\hline $\begin{array}{l}\text { SGR *Sustainable growth } \\
\text { rate }\end{array}$ & Sustainable Growth Rate & $\begin{array}{l}\text { ROE x (1 - Dividend- } \\
\text { Pay-Out Rate). }\end{array}$ & Rasio \\
\hline $\begin{array}{l}\text { RMP in operating } \\
\text { activities }(R M P C F O) \text { to } \\
\text { total liabilities }(T L)\end{array}$ & $\begin{array}{l}\text { Indicates company's ability to } \\
\text { cover its total debt with cash. }\end{array}$ & $\mathrm{CFO} / \mathrm{TL}$ & Rasio \\
\hline $\begin{array}{l}\text { RMP in Investing } \\
\text { activities (IA) to total } \\
\text { liabilities (TL) }\end{array}$ & $\begin{array}{l}\text { Measures the cash generated } \\
\text { from investing activities to } \\
\text { meet its obligation in the long } \\
\text { run }\end{array}$ & $\mathrm{CFI} / \mathrm{TL}$ & Rasio \\
\hline $\begin{array}{l}\text { RMP in Financing } \\
\text { activities }(R M P C F I) \text { to } \\
\text { total liabilities }(T L)\end{array}$ & $\begin{array}{l}\text { Measures the cash generated } \\
\text { from financing activities to } \\
\text { meet its obligation in the long } \\
\text { run. }\end{array}$ & CFF/TL & Rasio \\
\hline $\begin{array}{l}\text { RMP in operating } \\
\text { activities }(R M P C F O) \text { to } \\
\text { shareholder's equity } \\
(E Q)\end{array}$ & $\begin{array}{l}\text { Measures the amount of cash } \\
\text { generated from shareholders } \\
\text { investment and future return } \\
\text { on equity. }\end{array}$ & $\mathrm{CFO} / \mathrm{EQ}$ & Rasio \\
\hline SIZE & $\begin{array}{l}\text { Ukuran Bank dengan } \\
\text { menggunakan total asset } \\
\text { perbankan }\end{array}$ & LNSIZE & Rasio \\
\hline
\end{tabular}

Sumber: Wickamasinghe dan Gunwardane, 2017

\section{Teknik Analisis Data}

Data yang dikumpulkan akan dianalisis menggunakan persamaan regresi data panel dengan persamaan penelitian sebagai berikut:

$$
\begin{gathered}
S G R_{i t}=\beta_{0}+\beta_{1} R M P C F O T L_{i t}+\beta_{2} R M P C F I T L_{i t}+\beta_{3} R M P C F F T L_{i t} \\
+\beta_{4} R M P C F F E Q_{i t}+\varepsilon_{i t}
\end{gathered}
$$

\section{Dimana:}

$S G R_{i t} \quad=$ Sustainable growth rate

RMPCFOT $L_{i t}=$ Risk management practices in operating cash flow

$R M P C F I T L_{i t} \quad=$ Risk management practices in Investing cash flow

$R M P C F F T L_{i t}=$ Risk management practices in Financial cash flow

$R M P C F F E Q_{i t}=$ Risk management practices in operating cash flow to shareholder's equity

$\varepsilon_{i t} \quad=$ Error term

$\beta_{0} \quad=$ The minimum change in $\mathrm{Y}$ when the rest of the variables are held at a constant zero.

$\beta \quad=$ Measure of the rate of charge

\section{Uji Persamaan Penelitian}

Untuk menguji kelayakan persamaan penelitian tersebut di atas sebelum digunakan untuk analisis data dan sebagai dasar uji hipotesis, maka beberapa uji dilakukan yaitu uji chow, uji housman, uji normalitas dan uji gejala klasik untuk persamaan penelitian di atas. Uji normalitas residual tidak dilakukan karena jumlah data observasi penelitian adalah 114 observasi sehingga melebihi dari 30 Data Obeservasi, maka berdasarkan Central Limit Theorem, data yang melebih 30 Observasi bisa diasumsikan distrubisi data adalah normal. Dengan demikian, dalam hal ini digunakan asumsi bahwa data observasi diatas 30 adalah normal. (Wooldridge, 2005). Berdasarkan Teori Central Limit Theorem 
tersebut, maka penelitian ini tidak menggunakan Uji Normalitas. Uji gejala klasik yang dilakukan pada persamaan tersebut adalah uji multicolinearitas, uji heteroskedastisitas, dan uji otokorelasi. Tujuan uji gejala klasik tersebut adalah agar hasil persamaan penelitian bisa memenuhi unsur BLUE (Sakaran, 2010).

Uji Hipothesis, Uji hipotesis Ha1, Ha2,Ha3 dan Ha4 menggunakan uji t.

\section{HASIL DAN PEMBAHASAN \\ Sampel Penelitian}

Bank konvensional yang go pubik di BEI adalah sebanyak 38 bank. Dalam penelitian ini, sampel penelitian adalah semua bank konvensional yang go publik tiga tahun terakhir yaitu tahun 2017 - 2019 di BEI. Berikut daftar bank-bank yang jadi sampel penelitian selama tiga tahun atau sebanyak 114 observasi.

\section{Statistik Deskriptif}

Statistik deskriptif dari variabel penelitian dapat dilihat pada tabel 4.2 di bawah ini. Jumlah observasi 114 dengan rata-rata masing-masing variabel dapat dilihat di bawah ini.

Tabel 2. Deskriptif Statistik Variabel Penelitian

\begin{tabular}{lcccccc}
\hline \multicolumn{1}{c}{ SGR } & \multicolumn{1}{c}{ RMPCFOTL RMPCFITL RMPCFFTL RMPCFOEQ } & LNSIZE \\
\hline Mean & 0.033822 & -0.004286 & -0.015685 & 0.027224 & $2.41 \mathrm{E}-11$ & 24.25360 \\
Median & 0.043367 & -0.001700 & -0.002560 & 0.000824 & $4.85 \mathrm{E}-14$ & 23.97277 \\
Maximum & 0.219646 & 0.209905 & 0.139150 & 1.067169 & $1.57 \mathrm{E}-09$ & 27.96172 \\
Minimum & -0.362216 & -0.292206 & -1.272669 & -0.026858 & $-5.39 \mathrm{E}-12$ & 20.03689 \\
Std. Dev. & 0.083204 & 0.078752 & 0.126417 & 0.111321 & $1.51 \mathrm{E}-10$ & 1.869392 \\
Skewness & -1.922132 & -0.334416 & -8.723799 & 7.647808 & 9.524492 & 0.171757 \\
Kurtosis & 8.664745 & 4.362288 & 87.35914 & 69.11414 & 96.80389 & 2.280949 \\
Sum & 3.855672 & -0.488607 & -1.788053 & 3.103550 & $2.75 \mathrm{E}-09$ & 2764.910 \\
Sum Sq. Dev. & 0.782297 & 0.700814 & 1.805877 & 1.400338 & $2.58 \mathrm{E}-18$ & 394.8927 \\
Observations & 114 & 114 & 114 & 114 & 114 & 114 \\
\hline
\end{tabular}

Sumber: Diolah Sendiri

\section{Korelasi Antar Indenpedent Variable}

Korelasi antar variabel penelitian dapat dilihat pada tabel 4.3. di bawah ini. Dari korelasi tersebut terdapat tiga variabel saling berhubungan yaitu variabel independen RMPCFITL dengan RMPCFFTL, antara variabel RMPCFITL dengan RMPCFOEQ, dan antara RMPCFFTL dengn RMPCFOEQ.

Tabel 3. Korelasi Antar Variabel Indepeden Penelitian

\begin{tabular}{cccccc}
\hline \multicolumn{7}{c}{ RMPCFOTL } & RMPCFITL & RMPCFFTL & RMPCFOEQ & LNSIZE \\
\hline RMPCFOTL & 1 & & & & \\
RMPCFITL & -0.40071 & 1 & & & \\
RMPCFFTL & 0.17717 & $\mathbf{- 0 . 8 5 8 1 7}$ & 1 & & \\
RMPCFOEQ & 0.22857 & $\mathbf{- 0 . 9 2 3 4 6}$ & $\mathbf{0 . 9 4 3 7 9}$ & 1 & \\
LNSIZE & 0.05142 & 0.13853 & -0.22067 & -0.22357 & 1 \\
\hline
\end{tabular}

Sumber: Diolah Sendiri

Tiga variabel independen yang memiliki koefisien korelasi yang tinggi, maka ketiga variabel ini harus diletakkan masing-masing dalam satu persamaan regresi data panel. Dengan demikian persamaan penelitian semula satu persamaan menjadi tiga persamaan penelitian sebagai berikut:

Persamaan dasar dari peneitian ini adalah sebagai berikut:

$$
\begin{aligned}
\text { SGR }_{i t}=\beta_{0} & +\beta_{1} \text { RMPCFOTL }_{i t}+\beta_{2} \text { RMPCFITL }_{i t}+\beta_{3} \text { RMPCFFTL }_{i t}+\beta_{4} \text { RMPCFFEQ }_{i t} \\
& +\beta_{5} \text { LNSIZE }_{i t}+\varepsilon_{i t}
\end{aligned}
$$

Dipecah menjadi Tiga Persamaan Penelitian yaitu, Persamaan Pertama sebagai berikut:

Persamaan Kedua

$$
S G R_{i t}=\beta_{0}+\beta_{1} \text { RMPCFOTL } L_{i t}+\beta_{2} \text { RMPCFITL } L_{i t}+\beta_{5} L_{N S I Z E_{i t}}+\varepsilon_{i t}
$$

Persamaan Ketiga:

$$
S G R_{i t}=\beta_{0}+\beta_{1} \text { RMPCFOTL }_{i t}+\beta_{3} \text { RMPCFFTL }_{i t}+\beta_{5} \text { LNSIZE }_{i t}+\varepsilon_{i t}
$$

$$
S G R_{i t}=\beta_{0}+\beta_{1} R M P C F O T L_{i t}+\beta_{4} R M P C F F E Q_{i t}+\beta_{5} L N S I Z E_{i t}+\varepsilon_{i t}
$$




\section{Hasil Persamaan Regresi}

Persamaan regresi yang dihasilkan dalam penelitian ini sudah melalui tahap pengujian gejala klasik yaitu uji Multikolinearitas, uji Otokorelasi dan uji heteroskedastisitas.

\section{1) Uji Chow}

Hasil uji chow untuk ketiga persamaan regresi dapat dilihat pada tabel 4.4. persamaan satu sampai dengan persamaan tiga dilanjutkan ke uji Housman yaitu:

Tabel 4. Hasil Uji Chow

\begin{tabular}{ccrlrrl} 
No & Persamaan & \multicolumn{2}{c}{ Cross-Section F } & \multicolumn{2}{c}{$\begin{array}{c}\text { Cross-section Chi- } \\
\text { Pquare }\end{array}$} & \multirow{2}{*}{ Kesimpulan } \\
\cline { 5 - 6 } & & Stat & Prob & \multicolumn{1}{c}{ stat } & Prob. & \\
\hline 1 & 1 & 1.789343 & 0.0173 & 73.586217 & 0.0003 & Sign, lanjut ke Uji Housman \\
2 & 2 & 1.803248 & 0.0161 & 74.006783 & 0.0003 & Sign, lanjut ke Uji Housman \\
3 & 2 & 12.384622 & 0.0000 & - & - & Sign, lanjut ke Uji Housman \\
\hline
\end{tabular}

\section{2) Uji Housman}

Hasil uji Housman ketiga persamaan penelitian dapat dilihat pada tabel 4.5 di bawah ini,

Tabel 5. Hasil Uji Housman

\begin{tabular}{ccccc}
\hline \multirow{2}{*}{ No } & $\begin{array}{c}\text { Persamaan } \\
\text { Penelitian }\end{array}$ & \multicolumn{2}{c}{$\begin{array}{c}\text { Cross-Section } \\
\text { Radom }\end{array}$} & Kesimpulan \\
\cline { 3 - 4 } & & Stat & Prob & \\
\hline 1 & 1 & 7.677363 & 0.0532 & Tidak sign, gunakan random effect model \\
2 & 2 & 6.245196 & $\mathbf{0 . 1 0 0 3}$ & Tidak sign, gunakan random effect model \\
3 & 3 & 0.000000 & 1.0000 & Tidak sign, gunakan random effect model \\
\hline
\end{tabular}

\section{Hasil Persamaan Regresi}

Hasil regresi yang diperoleh menggunakan random effect model untuk ketiga hasil persamaan penelitian tersebut di atas. Hasil regresi dari ketiga persamaan penelitian dapat dilihat pada tabel 4.6. dari tabel hasil regresi tersebut dapat dilihat bahwa variabel praktek manajemen rsiko dari aktivitas operasi kepada pemegang saham dan manajemen risiko akivitas dari investasi dan pembiayaan dan ukuran bank juga memengaruhi sustainable growth rate.

\section{Tabel 6. Hasil Regresi Random Effect Data Panel}

Dependent Variable: SGR

Method: Panel EGLS (Cross-section random effects)

Date: 11/02/20 Time: 12:58

Sample: 20172019

Periods included: 3

Cross-sections included: 38

Total panel (balanced) observations: 114

\begin{tabular}{|c|c|c|c|c|c|c|}
\hline \multirow[b]{2}{*}{$\begin{array}{c}\text { Variabel } \\
\text { Independent }\end{array}$} & \multicolumn{2}{|c|}{ Persamaan 1} & \multicolumn{2}{|c|}{ Persamaan 2} & \multicolumn{2}{|c|}{ Persamaan 3} \\
\hline & Cof. & $\begin{array}{l}\text { T-stat } \\
\text { Prob }\end{array}$ & Cof. & $\begin{array}{l}\text { T-stat } \\
\text { Prob }\end{array}$ & Cof. & $\begin{array}{l}\text { T-stat } \\
\text { Prob }\end{array}$ \\
\hline $\mathrm{C}$ & -0.447515 & $\begin{array}{r}-6.799013 \\
0.0000\end{array}$ & -0.437638 & $\begin{array}{r}-6.503448 \\
0.0000\end{array}$ & -0.432668 & $\begin{array}{r}-6.567937 \\
0.0000\end{array}$ \\
\hline MRPCFOTL & 0.104971 & $\begin{array}{r}1.767973 \\
0.0798 \\
\end{array}$ & 0.067470 & $\begin{array}{r}1.205598 \\
0.2306 \\
\end{array}$ & 0.069166 & $\begin{array}{r}1.398220 \\
0.1649 \\
\end{array}$ \\
\hline MRPCFITL & 0.125887 & $\begin{array}{r}3.463118 \\
0.0008 * * *\end{array}$ & & & & \\
\hline MRPCFFTL & - & - & -0.142520 & $\begin{array}{l}-3.431465 \\
0.0008 * * *\end{array}$ & & \\
\hline MRPCFOEQ & - & - & & & -99685234 & $\begin{array}{l}-5.699664 \\
0.0000 * * *\end{array}$ \\
\hline LNSIZE & 0.020076 & $\begin{array}{r}.4282070 \\
.0000 * * *\end{array}$ & 0.019730 & $\begin{array}{r}7.150168 \\
0.0000^{* * *}\end{array}$ & 0.019484 & $\begin{array}{r}7.541774 \\
0.0000^{* * *}\end{array}$ \\
\hline
\end{tabular}




\begin{tabular}{|l|r|r|r|}
\hline R-squared & 10.395007 & 0.390095 & 0.393006 \\
\hline Adjusted R-squared & 0.378507 & 0.373462 & 0.376451 \\
\hline S.E. of regression & 0.042259 & 0.042087 & 0.042307 \\
\hline F-statistic & 23.94012 & 23.45203 & 23.74026 \\
\hline Prob(F-statistic) & 0.000000 & 0.000000 & 0.000000 \\
\hline Durbin-Watson stat & 1.973616 & 1.946057 & 1.952422 \\
\hline
\end{tabular}

\section{Hasil Uji Gejala Klasik}

\section{1) Uji Multikolinearitas}

Hasil uji multikolinearitas dari ketiga persamaan penelitian tersebut dapat dilihat pada tabel 4.3. Dari tabel tersebut terdapat tiga variabel yang memiliki korelasi cukup kuat. Untuk mengatasi multocilinearity ini, maka dilakukan pemisahaan independen variabel tersebut dalam persamaan regresi tersendiri sehingga persamaan penelitian ini menjadi tiga persamaan. Ketiga variabel tersebut adalah vaiabel MRPCFITL, CFOFFTL dan MRP CFOEQ.

\section{2) Uji Otokorelasi}

Hasil uji otokorelasi menggunakan Durbin-Watson pada tabel 4.6 diatas, menunjukkan statistik obeservasi dari uji DW masing-masing persamaan 1,2, dan 3 adalah 1,973616, 1,946057, dan 1,952422. Sehingga angka DW statitistik dari ketiga persamaan tersebut adalah diantara 1,54-2,46 sehingga tidak ada gejala otokorelasi.

\section{3) Uji Heteroskedastisitas}

Hasil uji heteroskedastisitas ketiga persamaan tersebut menujukkan tidak ada hubungan residual hasil persamaan regresi 1, 2, dan 3 dengan masing-masing independen variable nya. Dengan demikian tidak ada gejala heteroskedasitas dari ketiga hasil regresi tersebut.

\section{4) Uji Hipotesis}

Hasil uji hipothesis Ha1 menunjukan bahwa risk management pratices dalam operating cash flow tidak berpengaruh terhadap sustainable growth rate pada tingkat singnifikan $10 \%$. Hal ini terlihat dari tabel 4.6 dimana variabel MRPCFOTL tidak signifikan alpha 10\% mempengaruhi SGR, sehingga Ha1 diterima ditolak. Hasil uji hipotesis $\mathrm{Ha} 2$ dimana dihipotesiskan pengaruh risk management practice dalam investing cash flow berpengaruh terhadap SGR, hasilnya adalah berpengaruh signifikan positif pada tingkat alpha $1 \%$, sehingga $\mathrm{Ha} 2$ diterima . Hasil Uji $\mathrm{Ha} 3$ dimana risk management practice dalam kegiatan arus kas financing berpengaruh terhadap SGR perbankan dapat diterima pada tingkat signifikan alpha $1 \%$. Hasil uji Ha4 yang menyatakan bahwa pratik manajemen risiko dalam arus kas operasi kepada pemegang saham berpengaruh terhadap SGR dapat diterima pada tingkat signifikan alpha $1 \%$.

1. Analisis Dampak Risk management practices in Operating cash flow to Total Liability terhadap Sustainable Financial Performance

Hasil penelitian ini menunjukkan hasil bahwa praktek manajemen risiko dalam aktivitas cash flow operating tidak berdampak kepada sustainable financial performance perbankan. Hal ini karena kegiatan arus kas bersih belum mengeluarkan dana yang akan digunakan untuk investasi dan untuk pembayaran utang. Sustainable finance performance sangat tergantung ada dana arus kas operasi yang akan di reinvested kan lagi ke perusahaan. Semakin besar risiko manajemen dalam cash flow investasi akan semakin meningkatkan sustainable financial performance-nya. Tingginya cash flow operating belum menjamin tingginya cash flow investing dan financing. Jadi hubunganya bisa berlawan bisa juga tidak berlawanan. Hasil penelitian ini tidak sesuai dengan hasil penelitian Wickramasinghe dan Gunawardane (2017). Hasil penelitian juga tidak sesuai dengan hasil penelitian Eveline dan Ramli (2018) yang menyataan bahwa cash flow berpengaruh terhadap sustainable growth rate atau sustainable finance performance.

\section{Analisis Dampak Risk management practices in Investing cash flow to Total Liability} terhadap Sustainable Financial Performance

Dampak investing cashflow to total liability terhadap sustainable financial performance adalah positif. Ini mengindikasikan bahwa semakin tinggi cash flow investing to total liability maka semakin rendah risk management practice in investing cash flow, rendahnya risk managemet practice in CFI karena CFI nya tinggi disebabkan banyak divestasi sehingga divestasi ini akan membawa meningkatnya sustainable finance performance perbankan. Artinya praktik risk management yang terkait dengan cash flow investing berdampak negatif terhadap sustainable financing performance. 
Dampak negatif ini apabila divestasi tersebut terkait dengan aktiva yang tidak produktif. Kenaikan cash flow investing karena adanya divestasi menyebabkan risk managemet pratice mengalami penurunan sehingga sustainable financing performance perbankan mengalami kenaikan. Dampak negatif risk management terhadap sustainable financial performance artinya kenaikan cash flow investing akan menaikan sustainable financial performance. Dengan naiknya ratio cash flow investing to total liability akan menaikan keberlangsungan kinerja keuangan perbankan. Artinya pada industri perbankan, naiknya arus kas investing karena divestasi aset yang tidak produktif akan menaikkan sustanaible financial performance. Dengan kata lain turunnya arus kas investasi karena investasi pada aktiva tidak produtif akan mengurangi sustainable financial performance.

Hasil ini tidak sesuai dengan hasil Wickramasinghe dan Gunawardane (2017) dimana tidak ada dampak praktik risk management dalam Cash flow investing terhadap sustanaible financing performance perusahaan. Perbedaan ini karena tempat penelitian yang berbeda serta sampelnya adalah mewakili semua sektor industri yang listing di Bursa Efek Srilanka, sedangkan penelitian ini hanya pada sektor perbankan konvensional. Hasil penelitian ini sesuai dengan penelitian Shao (2018) dari sisi perspektif risiko keuangan dikaitkan dengan dengan sustainable financial performanace dimana semakin tinggi risiko keuangan akan menyebabkan perusahan akan gagal untuk mencapai sustainable financial performance perusahaan. Dari perspektif cash flow, penelitian Eveline dan Ramli (2018) menunjukkan hasil yang sama yaitu cash flow bisa memengaruhi sustainable financial performance. Dari prespektif kecukupan kas dimana akan semakin tidak cukup kas akan semakin berisiko sehingga berdampak juga pada sustainable financial performance. Dari hasil penelitian Wahyuni, Ika dan Dino (2016) ternyata kecukupan arus kas tidak berdampak pada sustainable growth rate atau dengan kata lain tidak berdampak pada sustanaible financial performance.

\section{Analisis Dampak Risk management practices in Financing cash flow to Total Liability} terhadap Sustainable Financial Performance

Rasio cash flow to liability mempunyai dampak negatif terhadap keberlangsungan kinerja keuangan perbankan. Semakin tinggi arus kas pembiayaan terhadap liability karena adanya tambahan hutang maka semakin rendahnya risk management practice nya, rendahnya risk management practice in Financial cash flow maka semakin rendah juga sustainable financial performancenya. Artinya praktek risk management dalam cash flow financing mempunyai hubungan signifikan positif terhadap keberlangsungan kinerja keuangan perbankan. Artinya semakin tinggi praktek risk management pada cash flow financing maka semakin tinggi pula keberlangsungan kinerja keuangan perbankan. Hal ini artinya semakin tinggi hutang yang menyebabkan cash flow dari financing semakin tinggi, maka semakin tinggi pula kerberlangsungan kinerja keuangan perbankan atau semakin baik. Hal ini sejalan dengan karakteristik dari industri perbankan dimana hutangnya bisa mencapai 80 sampai dengan $90 \%$ dari total asset bank, sehingga keberlangsungan kinerja keuangan perbankan tersebut dapat berlanjut.

Hasil ini tidak sesuai dengan hasil penelitian yang dilakukan oleh Wickramasinghe dan Gunawardane (2017), dimana hasilnya menyatakan bahwa dampak praktek risk management pada arus kas financing adalah negatif terhadap sustainable financing performance. Perbedaan ini karena sampel perusahaan semua sektor industri sehingga berlaku teori risk management dimana semakin tinggi risiko maka sustainable growth rate akan turun. Dalam penelitian ini hanya pada sektor perbankan, dimana dalam dunia industri perbankan yang penuh risiko, justru taking risk akan membawa dampak positif terhadap sustainable financial performance bank tersebut. Semakin berisiko maka semakin menaikkan net income bank tersebut sehingga tingkat reinvested-nya semakin tinggi.

\section{Analisis Dampak Risk management practices in Financing cash flow to Equity berpengaruh terhadap Sustainable Financial Performance}

Hasil penelitian ini menunjukan bahwa terdapat dampak negatif arus kas operasi terhadap equity terhadap sustainable financing performance. Artinya semakin tinggi arus kas operasi terhadap equity maka semakin rendah sustainable financing performance nya. Tingginya arus kas operasi tehadap equity menandakan rendahnya praktek risk management pada arus kas operasi to equity. Dengan demikian semakin rendah praktik risk management pada arus kas operasi terhadap stock holder equity maka semakin rendah juga sustainable financing performance perbankan tersebut begitu sebaiknya. Semakin tinggi risk management practice terkait dengan cash flow operating to shareholders maka semakin tinggi pula sustainable financial performance perbankan.

Hasil ini tidak sesuai dengan hasil penelitian yang dilakukan oleh Wickramasinghe dan Gunawardane (2017), dimana hasilnya menyatakan bahwa dampak praktik risk management pada arus 
cash operating in equity adalah negatif terhadap sustainable financing performance. Perbedaan ini karena sampelnya adalah perusahaan semua sektor industri yang ada di Sri Lanka sehingga berlaku teori risk manajemen dalam hasil penelitian Wickramasinghe dan Gunawardane (2017), dimana semakin tinggi risiko maka sustainable growth rate akan turun. Dalam penelitian ini hanya pada sektor perbankan, dimana dalam dunia industri perbankan yang penuh risiko, justru taking risk akan membawa dampak positif terhadap sustainable financial performance bank tersebut karena adanya reinvestasi dari laba bersih oleh perbankan tersebut.

\section{Analisis dampak ukuran bank terhadap sustainable finacing performance}

Hasil empirik ini juga membuktikan bahwa hubungan positif ukuran bank terhadap sustainable financing performace perbankan. Bank besar cenderung lebih sustainable growth daripada bank kecil. Bank besar lebih banyak mempunyai jaringan, bank besar memliki trust lebih tinggi didalam pasar uang sehingga akses untuk medapatkan pinjaman lebih baik daripada bank kecil sehingga cash flow financing lebih tinggi dan sustainable financing performancenya lebh baik dari bank kecil.

\section{Kesimpulan, Implikasi, Keterbatasan Dan Saran Kesimpulan}

Hasil penelitian dapat disimpulkan sebagai berikut: 1. Praktek risk management dalam cash flow operating tidak berdampak pada keberlangsungan kinerja keuangan perbankan. 2. Praktek risk management dalam cash flow investing berdampak negatif terhadap kerberlangsungan kinerja keuangan perbankan. 3. Praktek risk management dalam cash flow financing berdampak positif terhadap keberlangsungan kinerja keuangan perbankan. Dan 4. Praktek risk management dalam cash flow operating to shareholder equity berdampak positif terhadap kerberlangsungan kinerja keuangan perbankan.

\section{Implikasi}

Hasil ini memberikan implikasi kepada manajemen bahwa risk management practice terkait dengan cash flow investing, cash flow financing serta cash flow operating terhadap pemegang saham akan berdampak kepada sustainable financial performance. Untuk menaikkan sustainable financing performance maka yang harus dilakukan manajemen bank adalah pertama meningkatkan ekspansi ke aktiva produktif yang sehat, apabila tidak maka akan menurunkan sustainable financing performance bank tersebut, Kedua, pihak manajemen bank dapat meningkatkan arus cash financing dengan menambah dana pihak ketiga dengan tingkat risiko lebih rendah dibandingkan dengan hutang jangka panjang bank tersebut. Misalnya pinjaman pada lembaga lainnya. Dan yang ketiga adalah melakukan upaya untuk meningkatkan cash flow operating dengan tidak menaikkan stockholder equity pada tingkat diatas capital adequacy ratio yang berlaku. Karena dengan demikian akan menurunkan praktik risk management terkait dengan arus kas operasi terhadap pemegang saham dan menaikkan sustainable financing performance. Implikasi lain adalah bank juga berusaha untuk melakukan ekspansi, yang mengakibatkan bertambahnya asset bank sehingga dapat meningkatkan sustainable financing performancenya.

\section{Keterbatasan}

Hasil penelitian ini mempunyai keterbatasan apabila digunakan untuk memprediksi keberlangsungan kinerja keuangan perbankan. Keterbatasan tersebut adalah sebagai berikut: 1. Belum dilakukan konfirmasi secara kualitatif terhadap hasil prediksi keberlangsungan kinerja keuangan perbankan ini. Konfirmasi secara kualitatif dilakukan dengan melakukan FGD dengan praktisi perbankan. Dan 2. Belum mempertimbangkan varabel lain yang juga memengaruhi keberlangsungan kinerja keuangan.

Saran

Saran dalam penelitian ini agar keterbatasan dapat dikurangi adalah sebagai berikut: 1. Perlu dilakukannya konfimasi kualitatif melalui FGD terhadap hasil prediksi dengan menggunakan hasil regresi penelitian ini untuk memprediksi keberlanjutan kinerja keuangan perbankan. Dan 2. Diharapkan untuk penelitian berikutnya dapat diperluas dengan menambah variabel kontrol leverage, profit margin, likuiditas, dan turn over asset perbankan.

\section{DAFTAR PUSTAKA}

Ahmad, Ahmad, Asifa Maqbool dan Javed Iqbal (2017), “The Impact of Risk Management on the Sustainable Growth Rate of Islamic Banks" Pakistan Journal of Islamic Research, Vol: 18, Issue: 2 p.62-69, , melalui 
https://www.researchgate.net/publication/322789466_The_Impact_of_Risk_Management_on_the_Sustai nable_Growth_Rate of_Islamic Banks .

Brigham, Eugene F. and Houston (2020), Fundamentals of Financial Management, 13th Edition

Burger, J. H.; Hamman, W. D. (1999): "The relationship between the accounting sustainable growth rate and the cash flow sustainable growth rate", South African Journal of Business Management, ISSN 2078-5976, African Online Scientific Information Systems (AOSIS), Cape Town, Vol. 30, Iss. 4, pp. 101-109, http://dx.doi.org/10.4102/sajbm.v30i4.761

Cronje, Tom, Apriani Atahau and Sparta (2017), Bank Lending - Theory and Practise 2e, Sydney Australia: McGrawHill.

Demireli, E.,\& OztUrk, B. (2009). "Value At Risk Methods In Risk Management And An Application”, Suleyman Demirel University The Journal of Faculty of Economics and Administrative Sciences. Turkey.

Eveline dan Ishak Ramli (2018), "Faktor-Faktor Internal Penentu Pertumbuhan Perusahaan Pertambangan Yang Terdaftar Di Bursa Efek Indonesia Tahun 2010-2014”, Jurnal Muara Ilmu Ekonomi dan Bisnis, Vol. 2, No. 1, April 2018: hlm 94-101

Freeman, R. E. (1984). Strategic Management: A Stakeholder Approach. Boston: Pitman.

Hillier, D., Grinblatt, M. and Titman, S. J. (2012). Financial markets and corporate strategy, McGraw-Hill education, UK.

HS Hastuti, Widy (2019), 'Pertumbuhan Penjualan Dan Arus Kas Operasi Terhadap Pertumbuhan Laba Pada Perusahaan Manufaktur Sub Sektor Logam Yang Terdaftar Di Bursa Efek Indonesia”, Jurnal Bisman Info, Vol. 6 No. 2 Juni 2019, p.61-66.

Hull, John C. (2018), Risk Management and Financial Institutions, $5^{\text {rd }}$ Edition, John Wiley and Sons.

Jenson, Michel C., (1986), "Agency Costs of Free Cash Flow, Corporate Finance, and Takeovers", The American Economic Review, Vol. 76, No. 2, Papers and Proceedings of the Ninety-Eighth Annual Meeting of the American Economic Association (May, 1986), pp. 323-329 (7 pages), Published By: American Economic Association, https://www.jstor.org/stable/1818789

Laplume, A.O., Sonpar, K., \&Litz, R.A. (2008). Stakeholder theory: Reviewing a theory that moves us, Journal of Management.

Manaf, Normaisarah Binti Abdul, Noriza Binti Mohd Saad, Nor Edi Azhar Binti Mohamad, Inaliah Binti Mohd Ali and Norfhadzilahwati Binti Rahim, (2018), "Determinants Of Sustainable Growth Rate (Sgr) By Using Zakon's Model To Encounter With Shariah Compliance Requirements For Shariah Securities Compliance Firms In Malaysia", International Journal of Industrial Management (IJIM), Volume 4, June 2018, p.6169.

Priyanto, Aldi dan Robiyanto (2020), "Faktor-Faktor Yang Mempengaruhi Sustainable Growth Rate Terhadap Perusahaan Manufaktur Di Bursa Efek Indonesia Periode 2015-2018", JIMEA, Jurnal Ilmiah MEA (Manajemen, Ekonomi, dan Akuntansi), Vol. 4 No. 2, p.1-21.

Sakaran, Uma and Roger Bouquie (2010), Research Methods for Business-a skill building approach, fith edition, India: Willey.

Shao , Zhengyan, (2018), "An Empirical Study of the Sustainable Growth ofListed Companies in Textile and Garment Industry in the Post-crisis Era"., Advances in Intelligent Systems Research (AISR), volume 160, p.253-258., 3rd International Conference on Modelling, s imulation and Applied Mathematics (MSAM 2018),Published by Atlantis Press, http://creativecommons.org/licenses/by-nc/4.0/).

Sounders, Anthony and Marcia Millon Cornett, (2018), Financial Institutions Management: A Risk Management Approach, Ninth Edition, New York: McGraw-Hill Education.

Subbareddy, K dan M. Kishore Kumar Reddy, (2017), "Sustainable Growth Rate and Firm Performance", National Conference on Marketing and Sustainable Development, October 13-14, ISBN 978-1-943295$10-4$, p.647-652, malalui

file:///D:/data/proposal\%20kegiatan\%20dan\%20penelitian/proposal\%20penelitian/proposal\%20peneltia n\%20Ibs/08-proposal\%20penelitin\%20sparta\%20ibs-feb\%202020/9-

jurnal\%20sustainable $\% 20$ growht $\% 20$ rate $\% 20$ and $\% 20$ cash $\% 20$ flow/Sustainable\%20Growth $\% 20$ Rate $\% 2$ 0and\%20Firm\%20Performance.pdf

Vural, O. (2004). "Cash Flow-At-Risk In Publicly Traded Non-Financial Firms In Turkey: An Application In Defense Companies, (Unpublished Master's Thesis). The Institute of Economics and Social Sciences, Master Of Business Administration, Bilkent University, Turkey.

Wadesango N, Tinarwo N, Sitcha L, and Machingambi S, (2019), "The Impact Of Cash Flow Management On The Profitability And Sustainability Of Small To Medium Sized Enterprises", International Journal of Entrepreneurship, Volume 23, Issue 2/2019, p.1-19.

Wahyuni, Nining Ika dan Nova Victor Geral Dino (2016), Determinant Of The Sustainable Growth Rate, The $1^{\text {st }}$ International Confrence on Business and Accounting Studies, Facuty of Economics and Business University of Jember. P.401-416, melalui https://repository.unej.ac.id/bitstream/handle/123456789/79079/Nining\%20Ika\%20W_Proceeding\%20Th 
e\%201th\%20International\%20Conference\%20on\%20Business\%20and\%20Accounting\%20Studies\%20 1 .pdf? sequence $=1$.

Wickamasinghe, Manjula Bandara dan Kennedy Gunwardane (2017). Cash Flow Risk Management Practices on Sustainable Financial Performance in Sri Lanka, International Journal of Arts and Commerce Vol. 6 No. 8 November 2017

Wooldridge, Jeffrey M.,(2005), Introductory Econometrics- a Modern Approach. 5 edition, United Stated of America: Thompson Learning 